\title{
CONTRIBUTION OF THE NATIONAL INSTITUTE FOR NUCLEAR, CHEMICAL AND BIOLOGICAL PROTECTION TO THE DEVELOPMENT OF METHODS AND PROCEDURES RELATED TO SAFETY ENGINEERING
}

The paper describes the National Institute for Nuclear, Chemical and Biological Protection involvements with regards to the development of methods and procedures related to Safety Engineering. It provides general information about the Institute's activities, history, presence and objectives for the near future to illustrate its role, tasks and responsibilities. The Institute's added values that consist in its share to the reduction of safety risks and incident consequences are presented and discussed in details.

\section{Introduction}

The main objective of the National Institute for Nuclear, Chemical and Biological Protection is to contribute to the protection of people and the environment against hazard under specific conditions, in which chemical, biological, radiological, nuclear $(\mathrm{CBRN})$ substances and explosives are involved. Safety Engineering, according to various definitions in the literature, refers to any act of accident prevention with an obvious goal to increase the safety of operations, processes, systems, etc. Within this meaning, the Institute research activities concentrate on the methods and procedures closely related to this field of engineering.

It is evident that human activity will always unavoidably involve risks to safety. Improving the safety means reducing the risk. If all risks cannot be fully eliminated it should be interpreted that fewer fatalities, injuries and less damage occur to the property and the environment in case of an incident.

\section{The background}

It is a common routine of the authors dealing with the problem of the protection against CBRN substances to stress their potential abuse (terrorism) or to quote facts of their releases/spills in the past - either as a result of industrial or natural disasters. We do not consider it necessary to impress upon the readers the necessity of reasonable readiness of the society for such a potential incident. The following facts may probably have a more informative value about the attention paid to the protection against CBRN substances than any citations of the literature, normative acts, scientific authorities and historical events.
1. Starting in 2007 , the EU will spend approximately $€ 200$ million per year for dual-use homeland security research projects. The EU money will be spent on technologies to support four broad missions:

- border security;

- protection of critical infrastructure;

- crisis management;

- anti-terrorism/counter-crime.

A substantial part of this amount will be funding civil-military emergency response projects against biological, chemical and nuclear threats ${ }^{1)}$.

2. There is an enormous quantity of publications in the literature and, if you put the key words (e.g. CBRN, weapons of mass destruction, NBC protection, terrorism, etc.) in the most common search engines on the world web, you may receive tens to hundreds of million references.

The issue of the protection against CBRN substances is very comprehensive and complex. On top of that, there exist lots of conventions, treaties, decisions, recommendations, etc. for each individual group of these substances, i.e. chemical, biological, radiological and nuclear ones, adopted at the international level and a corresponding number of various organisations controlling their observance. These organisations lay down different requirements for handling the individual groups of CBRN substances. Heterogeneousness of the requirements is due to the time of establishment and different historical development of the relevant organizations. The non-proliferation regimes according to the Australia Group applied through the national export systems of the participating states - and the treaty based regimes in the case of the Chemical

\footnotetext{
* Stanislav Bradka, Tibor Mikes

National Institute for Nuclear, Chemical and Biological Protection, Milin, Czech Republic, E-mail: sujchbo@sujchbo.cz

1) See e.g. http://www.seceur.info/
} 
Weapons Convention ${ }^{2)}$ (CWC) or the Biological and Toxin Weapons Convention $^{3)}$ (BTWC) can serve as an example.

There are only a few countries in the world (and the Czech Republic is one of them) that are striving for the implementation of the internationally adopted principles from one centre. The supervision over the peaceful use of CBRN substances in the Czech Republic (CR) in compliance with international conventions stays within the competency of the State Office for Nuclear Safety (hereinafter the Office). The Office, apart from the supervision over the utilisation of nuclear power and nuclear materials, executes also the function of the National Authority of the Czech Republic for the implementation of the CWC and since 2002 it has also been fulfilling this task in relation to the implementation of the BTWC. The priorities of the Office are, from this point of view, strict controls of industrial facilities, import and export organisations, laboratories and other facilities where nuclear, chemical and biological substances are handled. Such controls should exclude any malpractice both from the respect of fulfilment of the objectives and the subject-matter both of the national legislation and the adopted international obligations.

Technical aspects of the supervision performed by the Office in the field of radiation protection and control of the observance of prohibition of chemical weapons and bacteriological (biological) and toxin weapons are guaranteed in a large extent by the National Institute for Nuclear, Chemical and Biological Protection (hereinafter the Institute or SUJCHBO, v.v.i ${ }^{4)}$.) established by the Office. The current organisational structure of the Institute (except for some elements like the Board and the Supervisory Board) was established only in 2000; nevertheless it has more than a fifty-year old history. The Institute's existence is closely linked to the boom of the uranium industry in the Czech Republic when the predecessor of SUJCHBO, v.v.i. provided mainly monitoring of miners under extreme climatic conditions. After the reduction of uranium ore mining at the beginning of the nineteen-nineties, the Institute transformed to providing expertises and responses to emergences. The transformation was successfully concluded during 2000 when the Institute's scope of activities was gradually getting narrower and specialised in the three fields: nuclear, chemical and biological protection. Concurrently, the Institute's instrumentation for the aforementioned activities got improved, its capabilities got extended and the Institute has become the main technical support body to the Office.

\section{The contribution}

SUJCHBO, v.v.i. as a public research institution (within the meaning of Act No. 341/2005 Sb ${ }^{5}$. on Public Research Institu- tions) has been designated to execute research and development activities focused basically on the identification and quantification of radioactive, chemical and biological substances for evaluation of their impact on persons and the environment since January 1 , 2007. To perform the aforementioned principal activity, the Institute solves, either individually or in co-operation with other entities, comprehensive research tasks.

Main research and development activities that have been recently completed and/or are still on schedule at both the national as well as international level include:

- Research project "Study of material and personal factors for personal protection against chemical and biological agents including their detection and identification", which is divided into five sub-projects:

- Methods for quantification of highly toxic chemical agents according to Schedule 1 of the CWC

- Identification and quantification of compounds of biological origin by Liquid chromatography mass spectrometry (LC-MS) method

- Elaboration of methods for rapid and effective detection of biological agents

- Study of permeation velocity of toxic agents and surrogates through the protective materials in order to estimate the reliable time of personal protection

- Physiological evaluation of effect of protective clothing inner layers' composition for the optimisation of their use

- Research project "Monitoring and evaluation of natural sources of ionizing radiation"

- Research project "Detection and identification of B agents by methods based on mass spectrometry" that is focused on detection and identification of B agents by MALDI-TOF mass spectrometry

- Research project "Protection against CBRN substances", which deals with specific requirements for the protection of First Responders

- The research project "Physiological aspects of personal protective equipment on their users"; its objective is to monitor the physiological behaviour of the user - the organism response to the workload, determination of usability or tolerance time to the protective means

- International research project "Innovative Measures for Protection Against CBRN Terrorism" (IMPACT) in the framework of Sixth Framework programme "Preparatory Action on the enhancement of the European industrial potential in the field of Security research" (PASR), where the main contribution of the Institute was in the area of CBRN decontamination.

It follows from the aforementioned that a decisive part of the Institute's activity is the research focused on evaluation and devel-

\footnotetext{
2) The commonly used term for the "Convention on the Prohibition of the Development, Production, Stockpiling and Use of Chemical Weapons and on their Destruction"

3) The commonly used term for the "Convention on the Prohibition of the Development, Production and Stockpiling of Bacteriological (Biological) and Toxin Weapons and on Their Destruction"

${ }^{4)}$ Acronym "v.v.i" stands for public research institution

${ }^{5)} \mathrm{Sb}$. stands for the Collection of Laws
} 
opment of personal and collective protective equipment agains CBRN substances, on their detection, identification and decontamination.

The secondary activity of the Institute is an activity performed in public interest, especially on the basis of demands of the competent organisational bodies of the state or territorial selfgoverning units with an objective to provide them professional support for their decision-making activities, assist in performing their tasks, including their education and training. Such activities are performed mainly by the Institute's involvement in the Integrated Rescue System of the Czech Republic (IRS CR).

As a part of other activities, SUJCHBO, v.v.i. also performs accredited and non-accredited tests and expertises, it organises professional courses, trainings and other educational events; performs consultancy, including research of partial problems related to its principal activity.

The Institute is a holder of relevant licences making it possible to handle and test otherwise prohibited chemical and biological agents or toxins. Meaningful research, development and testing of special protective equipment, investigation within the framework of the Institute's involvement in the IRS CR, as well as any other expertise in the given field, can be performed only under these conditions.

The Institute's laboratories have a Europe-widely recognized accreditation for the below listed activities. SUJCHBO, v.v.i. has also been authorized by the Office for Technical Standardisation, Metrology and State Quality Control as a metrological centre for calibration, verification and technical examination of the determined gauges of radon volume activity and radon equivalent volume activity.

Professional activities of the Institute are performed by the departments of nuclear, chemical and biological protection and an independent department of monitoring support.

- Nuclear Protection Department is focused on radon measurement and evaluation of its abundance, preparation, processing and evaluation of track detectors within the Radon Programme of the CR and beyond such programme. It also carries out personal dosimetry and monitoring of the environment in the vicinity of ionizing radiation sources, as well as both laboratory and field measurements of radioactivity.

- Chemical Protection Department and its laboratories are focused on detection, identification and quantification of highly toxic chemical agents in the working and natural environment. These activities are carried out both in laboratory and field conditions. It also evaluates quality of chemical and other special personal and collective protective equipment as well as quality of critical infrastructures protection. The department elaborates methods for their testing and participates in their development and standardization. Significant activity of the department is its support to the supervision exercised by the Office staff according to Act No. 19/1997 Sb. as amended.
- Biological Protection Department is focused especially on protection of persons under extreme conditions, including evaluation of personal protective equipment from the point of view of working and heat load. Besides, the department deals with detection and identification of biological agents and toxins. Such activity is utilised for the development of biological agents' detection methods and for supporting the supervision exercised by the inspectors of the Office according to Act No. 281/2002 $\mathrm{Sb}$. as amended.

- Independent department of monitoring support conducts measurements in the vicinity of former and existing regions of uranium industry and mining works. It processes the results from the entire territory of the country, provides inspections, as well as support to the Radiation Monitoring Network of the Czech Republic in an air monitoring.

The Institute co-operates, within agreements concluded with other government departments, especially with the Ministry of Interior - General Directorate of the Fire Rescue Service of the Czech Republic, in solving all serious issues related to CBRN substances.

After the terrorist attacks in the USA on $11^{\text {th }}$ September 2001 and after the subsequent wave of "anthrax consignments", such a "campaign" did not avoid the Czech Republic either. The first consignments appeared only about a month after the attack, and during the next three months, i.e. from October 15, 2001 to January 14, 2002, the Fire Rescue Service and/or the Police of the Czech Republic registered 2175 suspicious consignments. Due to its capabilities, instrumentation and its scope of activities, making it possible to analyse all possible components of the suspicious consignments in one site, the central Crisis Staff of the Czech Republic designated the Institute for collection and analyses of "suspicious consignments" and/or any other abandoned suspicious packages (potentially dangerous items) from the whole territory of the country.

More than 8000 consignments have been transported, mostly by the IRS CR, to the Institute for expertises and identification of unknown substances so far. These consignments and found items were processed according to the approved procedure based on the safety at work principles. The whole line for processing the examined items is designed to maximally ensure safety of operators as well as working environment. The coating compounds applied in the used areas are resistant to chemicals, possible toxic agents and decontaminants. Collection of decontamination waste products is solved in compliance with relevant regulations and standards.

To enhance safety during risky operations, the Institute developed various specialized equipment. One of them is a remotely operated drilling unit fitted in an air-tight container that can be filled with inert gasses. The container is equipped with cameras in such a way that the whole system is resistant to chemicals and pressure to specified extent. It can be connected to the filter-ventilation system and/or to any reservoir (see Fig. 1 bellow). It is successfully used for opening cylinders with unknown content as well as suspicious ammunition with an indeterminable content or 
with a proved content of liquid. Though the examined ammunition found from World War II was smoke ammunition (filled with a mixture based on chlorsulphonic acid) in all the cases, it is generally known that the same artillery projectiles were also filled with bis(2-chloroethyl)sulphide (mustard gas).

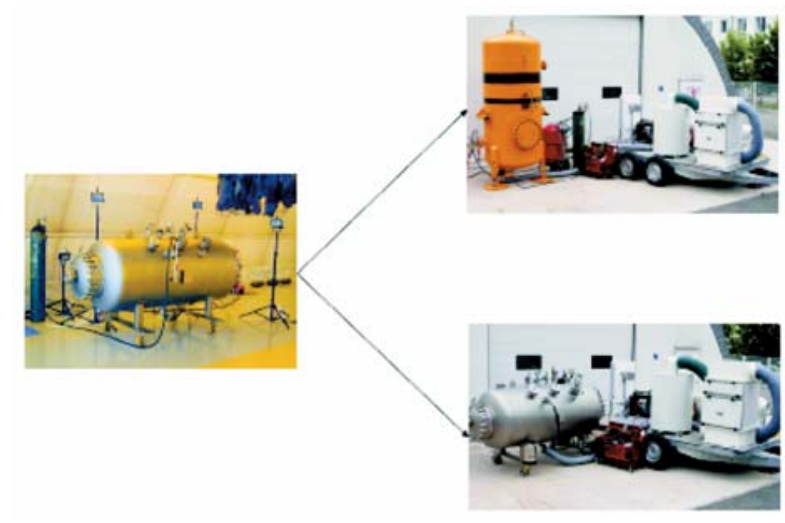

Fig. 1 Example of specialized equipment developed at the Institute

In the area of research and development the Institute closely co-operates with other research institutions of the Academy of Sciences and the Ministry of Defence of the Czech Republic, universities, especially the University of Defence, the South-Bohemian University in České Budějovice and the Faculty of Safety Engineering in Ostrava.

Among the Institute's basic achievements at the international level is its assistance to the Organisation for the Prohibition of Chemical Weapons (OPCW) and a bilateral co-operation with The Netherlands' Organisation for Applied Scientific Research (TNO). The Institute closely co-operated with well known European research institutes (EU Joint Research Centre JRC Ispra, the French Centre d'Etudes du Bouchet CEB, the Swedish Defence Research Agency FOI, Technical Research Centre of Finland VTT and others) within a multi-national consortium in PASR "IMPACT". In the last years, very significant was the co-operation of SUJCHBO, v.v.i. with Bruker Daltonics $\mathrm{GmbH}$. The Institute developed a database of highly hazardous biological agents for MALDI-TOF mass spectrometry system on the basis of Bruker's requirements and in co-operation with the company.

For the coming years the tasks and requirements of the Office will remain the Institute's activities priority. Nevertheless, the Board and the Management link the scope of the Institute's future activities and further development also with the most demanding tasks of the protection against CBRN substances at the international level. Thereby the future activities will focus on the development of:

- Realistic scenarios to face CBRN threats,

- Testing methods

- Training and exercises for complex systems being as close as possible to field conditions, with the following two main objectives:

1. Testing the quality of the protective materials and complex systems for CBRN protection

2. Contributing to the optimization of:

- the use of the existing and newly designed protective systems and materials,

- the methodologies for detection, identification and protection,

- studies concerning behaviour (distribution, stability, etc.) of CBRN substances and/or surrogates in the environment under different conditions,

- measurement/testing of the protective clothing and systems as well as cross-validation of the results,

- bulk systems testing in real conditions.

The Institute wants to be more engaged in some of the OPCW's activities, especially in providing training to international inspectors and/or experts of the aforementioned organisation. The staff is ready and willing to be more closely involved in the Organisation's special projects.

The nearest objective in the field of testing is to complete the construction of a laboratory for large-scale tests to be conducted under real conditions. The laboratory could also be used for the simulation of industrial accidents and testing of large-scale objects within e.g. the "European Technology Platform for Industrial Safety" (ETPIS). SUJCHBO, v.v.i. closely follows the activities within the new European Community Regulation on chemicals and their safe use "Registration, Evaluation, Authorisation and Restriction of Chemical Substances" (REACH) that entered into force on 1 June 2007. Here, we can also see certain possibilities in providing expertises and engaging the Institute's capacities in some of the tests, especially the ones related to chemicals determined by the CWC (i.e. the Scheduled Chemicals).

Increased attention will be paid to the European Commission's numerous calls-for-proposals through its Seventh Framework Programme for research (FP 7 2007-2013). The objective is to actively participate in the fields of security research related to the protection against CBRN substances. The Board and the Management of SUJCHBO, v.v.i. consider it as a chance for the Institute to influence and participate in the debate on a new EU-wide health and safety standards, requirements and best practices.

\section{Conclusions}

The Institute, since its foundation, has significantly contributed to the improvement of protection of people and the environment in case of intentional or accidental release of CBRN substances. It has provided a wide range of expertise on security related sciences and research from general safety issues to security-oriented subjects. Its activities in the field of protection against hazardous substances are based on the following general principles: 
- Anticipate, identify and evaluate hazardous conditions and practices,

- Develop hazard control designs, methods, procedures and programmes,

- Implement, administer and advise others on hazard control programmes,

- Measure, audit and evaluate the effectiveness of hazard control programmes.
Testing various equipment complexes and modelling a wide range of behaviour of surrogates and real CBRN substances in the near future with the aim to acquire data for reduction of their impact on persons and the environment, should increase the quality of protection against such hazard. The expected research results should be usable not only for further development of science and technology, but mainly for concrete technologically feasible measures in the given field.

\section{References}

A number of internal documents of the Institute have been used for drafting this paper but with regard to the nature of the presented information none of them are publicly available yet. 